\title{
Information, communication, travel behavior and accessibility
}

\author{
Bert van Wee \\ Delft University of Technology
}

\author{
Karst Geurs \\ University of Twente
}

\author{
Caspar Chorus \\ Delft University of Technology
}

\begin{abstract}
:
Over the past two decades many papers have been published on the impact of Information and Communication Technologies (ICT) on travel behavior, but the literature focusing on the impact of ICT on accessibility is relatively scarce. In this paper we give an overview of the impact of ICT on four components of accessibility as distinguished by Geurs and van Wee (2004): (1) the land-use component, (2) the transportation component, (3) the temporal component, and (4) the individual component. Conclusions are that first much more literature exists on the potential impacts of ICT on travel behavior than on its impact on accessibility. Second, we argue that ICT potentially has an impact on all four components of the concept of accessibility. Literature exists on the direct impacts but fails to incorporate impacts due to the interactions between the accessibility components. Third, there seems to be a major challenge in developing accessibility measures and indicators that include ICT, including those that measure the utility of accessibility. Fourth, in the area of ICT's impact on travel behavior, many research gaps exist. Examples are the impact of ICT on overall activity and trip patterns, the impact of ICT on activities and trips at the household and social-network level, ICT as a means of avoiding congestion or mitigating its effects, and the role of the phenomenon of self-selection in the context of ICT use. Finally, a major challenge is to develop models for activities, including ICT-impacts, which combine high levels of behavioral realism with (econometric) tractability.
\end{abstract}

Keywords: ICT, accessibility, travel behavior

\section{Introduction}

A paramount goal of land-use and transport policies is to improve accessibility: the combined land-use and transport system should allow people to travel and participate in activities, and firms to transport goods between locations (from mining, via stages of production, to distribution centers, and finally to clients such as shops or other firms). However, despite the crucial role of accessibility in transport policymaking throughout the world, the concept is generally poorly defined. Indicators often only relate to the transport system: travel times, time loss due to congestion, and the chance of congestion being example indicators. This narrow-minded approach ignores the fact that several other useful categories of indicators for accessibility exist. Geurs and van Wee (2004) argue that proper definitions of accessibility generally should include (at least a selection of) four components: (1) a land-use component, (2) a transportation component, (3) a temporal component, and (4) an individual component. Focusing on passenger transport, we use the definition of accessibility provided by Geurs and van Wee
(2004): the extent to which land use and transport systems enable (groups of) individuals to reach activities or destinations by means of a (combination of) transport mode(s).

It is now generally recognized that Information and Communication Technologies (ICT) in its several forms may have an impact on activity patterns and travel behavior, along the lines of the four components of accessibility as distinguished by Geurs and van Wee (2004). For example, shops might relocate due to selling via the Internet, influencing people's location choices if they visit these shops (location component). If people work at home using ICT for part of the day and then commute, the time of day when travel occurs could change, in turn leading to changed travel times, and less congestion during peak hours (transport component). ICT might also change the time pattern of activities. For example, one can choose a product via the web at night even if shops are closed (temporal component). It should be noted that the use of ICT for several purposes is characterized by high levels of inter-individual heterogeneity. For example, young people generally adopt new individual ICT technologies, such as navigation systems, more

${ }^{\text {a }}$ g.p.vanwee@tudelft.nl 
easily than older people (individual component).

In this paper we argue that ICT can potentially have impacts on all the accessibility-related components presented above. Previous literature has focused on partial impacts of ICT on accessibility — to the best of the authors' knowledge no comprehensive overview of the impact of ICT on accessibility exists. This paper first aims to give such a systematic overview. However, before being able to give this overview, we first need to understand the impact of ICT on travel behavior-and we give an overview of the impact of ICT on travel behavior before highlighting potential impacts on accessibility. The second aim is to address the gaps in the literature in the area of the impact of ICT on travel behavior and accessibility, addressing the challenges for future research in the area of the impact of ICT on accessibility.

The scope of this paper is defined as follows: we discuss the impact of ICT on travel behavior from the perspective of its relevance for accessibility. Second, we exclude the impact of ICT on goods transport, even though this impact is also very important, and even though the impact of ICT on goods transport also affects passenger transport-related accessibility (Weltevreden and Rotem-Mindali, 2009). However, some of the categorizations and ICT impacts as described in this paper also apply to goods transport, the use of navigation systems being an example. In addition, we exclude from our analyses access to ICT (e.g., Pick and Azuri, 2008). Note that we do not review the literature by systematically presenting results in table form; rather, we include references in our line of reasoning, following the accessibility components of Geurs and van Wee (2004). Finally, we have an empirical, theoretical, and conceptual focus, and exclude methodological issues, such as data collection (see, for example, Kenyon, 2006).

The remaining part of this paper is organized as follows. Section 2 presents an overview of the literature on ICT and travel behavior. Section 3 gives an overview of the literature on accessibility. Section 4 then describes the potential impact of ICT on accessibility. Section 5 presents a conceptual model for the impact of ICT on accessibility. Section 6 presents the main conclusions of the paper.

\section{An overview of the literature on the im- pact of ICT on travel behavior}

This section presents an overview of the literature on the impact of ICT on travel behavior, clustered into a few categories of literature.
Transport policymakers have often hoped that ICT would provide a substitute for travel. Substitution certainly does occur. An example of research into the substitution of travel by ICT is found in De Graaff and Rietveld (2007) who focus on the substitution of working out of the home by working at home. They conclude that working at home and out of the home act as (slightly imperfect) substitutes, largely depending on characteristics of the individual. That is, working at home and out of the home seem to be more determined by individual characteristics than by commuting time and ICT availability. Notwithstanding high expectations, much of the early optimism about substitution has been reduced over time, one explanation being, as several authors have suggested, the preferences of people for face-to-face interactions (e.g., Graham and Marvin, 1996). It should be noted here that communication technology cannot fully compensate for the richness of face-to-face contact, in cases such as, for example, the conveyance of complex, nonstructured, or potentially ambiguous information (Boden and Molotch, 1994; Larsen et al., 2007; Aguilera, 2008). In addition, it has been well documented that ICT could also trigger the generation of travel. Its impact on the generation of additional travel might be even more important than its substitution effect. For example, Mokhtarian and Meenakshisundaram (1999) conclude that it is unlikely that ICT will reduce travel significantly. Early research on the impact of ICT on travel behavior and activity patterns, probably partly because of the high expectations of substitution effects, generally focused on issues like substitution versus the generation of commuter travel (e.g., Mokhtarian and Salomon, 1997; Mokhtarian and Varma, 1998). This focus can be explained for two reasons. First, commuter traffic causes the most road infrastructure capacity problems because of its concentration in time and also often in place. Second, additional motivations were air-quality issues (Mokhtarian, 1991) and energyuse considerations (Harkness, 1977; Kraemer, 1982; Lathey, 1977). Substitution could help to solve these problems. An example of the nowadays generally accepted concept of the complementarity of ICT and travel can be found in Farag et al. (2007), who carried out a study of shopping online and/or in-store. They found that searching online positively affects the frequency of physical shopping trips, which in its turn positively influences buying online. In addition it was found that e-shopping could be task oriented for some people, and leisure oriented for others.

In the early years, teleworking might have received the most attention in the literature, but early conceptual speculations and scenario studies of substitution potential have also included teleconferencing (e.g., Day, 1973; Polishuk, 1975; Alb- 
ertson, 1977; Harkness, 1977; Kraemer, 1982; Lathey, 1975). In addition to the conceptual speculation, at least two empirical studies of the impact of teleconferencing on travel appeared in the 1980s (Bennison, 1988, and Mokhtarian, 1988, which found a net impact of complementarity).

This focus was followed by a growing interest in shoppingrelated travel and activities (e.g., Ferrel, 2004; Rotem-Mindali and Salomon, 2007; Farag et al., 2007; Weltevreden and Rotem-Mindali, 2009), and the wider impact of ICT on activities, such as e-banking (e.g., Altinkemer, 2001). Nowadays it is generally recognized that ICT potentially has an impact on all kinds of activities, not only jobs and shopping but also recreation and others (Mokhtarian et al., 2006; Muhammed et al., 2008).

Other research has emphasized that new ICT services and applications do not have a clear-cut functional equivalent in the 'physical' world as many of the earlier ICT technologies did. This puts the substitution versus generation discussion into another perspective (Hjorthol and Gripsrud, 2009): New ICT services and applications, such as worldwide e-gaming might be just another activity that people might carry out instead of, for example, reading a book or watching TV. For more discussion on the issue of substitution versus generation we refer to Mokhtarian (2003; 2009).

\subsection{Multi-tasking, fragmentation}

Kenyon and Lyons (2007) argue that the impact on activity of ICT will not be fully understood if multitasking is ignored. In an empirical study, it was found that all participants report multitasking at some stage during a surveyed week. The authors conclude that, when primary activities alone (and not less important simultaneously carried out activities) are considered, the categories of activities in which time use is most underreported are communication, entertainment/recreation, information search, and shopping. It has also been hypothesized that these activities are susceptible to travel substitution effects, because of their propensity to be performed using ICT. They found that for 84 percent of the time an individual is traveling, (s)he will be conducting at least one parallel activity. In some cases these activities will constitute new time uses that otherwise would not have been conducted at all, and thus potentially have no impact on travel. Parallel activities while traveling could contribute to reducing the disutility of travel, and therefore increase travel at the margin (Lyons et al., 2007). Travel-related multitasking could be one explanation for observed increases (or stability) in per capita travel time (e.g., Metz, 2008; van Wee et al., 2006). Furthermore, the fact that ICT might enable multitasking while traveling is expected by many to have an impact on travelers' valuation of travel time (savings): More specifically, it seems intuitive that by enabling multitasking, ICT will decrease the value of travel time savings (VoTTS). Indeed, empirical research (Ettema and Verschuren, 2007) suggests that individuals who dislike multitasking have relatively high VoTTS. The authors, however, caution that much more research is needed in this area before more definitive conclusions can be drawn, for example, that self-selection processes could play a role.

Lenz and Nobis (2007) argue that ICT leads to a reorganization of activities in time and space, with a consequent impact on travel behavior. They discuss the concept of "fragmentation" as introduced by Couclelis (2000) and conclude that transport demand increases with the fragmentation of activities. They make a distinction between spatial fragmentation (fragmentation of activities over different locations), temporal fragmentation (fragmentation of activities over time) and fragmentation in the manner in which activities are performed (activities themselves can be carried out in different ways, for example, shopping physically versus e-shopping). Based on their empirical findings it is not clear whether the use of ICT leads to an increase in travel demand for people who already made a lot of journeys before the diffusion of ICT, or whether ICT has a small reducing effect on the very high mobility level of these people.

\subsection{Travel mode, route, and departure-time choice}

ICT may also have an impact on mode, route, and departuretime choices. For example, out-of-vehicle systems, such as dynamic information panels, mobile devices, or in-vehicle systems (satellite navigation-satnav), showing route information may affect people's route choice and reduce travel times by optimizing the use of road networks. Mobile or in-vehicle systems may also reduce search time for route information (substitution of route searching via the web by satnav systems). Initial policy expectations were that ICT would greatly contribute to a more efficient use of transport infrastructure by spreading travelers across modes, routes, and departure times (e.g., Commission of the European Communities, 2001; Federal Transit Administration, 2003; Department for Transport, 2004). However, a stream of theoretical and empirical research (e.g., Chorus et al., 2006a, 2006b; Farag and Lyons, 2010) shows that policy expectations may need to be adjusted downward. Information acquisition is costly in terms of time, effort, attention, and in some cases money, and travelers often ignore the available information. See, for example, a study by Chatterjee and McDonald (2004) that shows that awareness levels of information provided through variable message signs can be as low as 33 
percent. It is possible that the level of awareness of navigation systems (and maybe more mobile ICT services) is significantly higher. To the best of our knowledge this is a blind spot in the literature. On a more positive note, a laboratory study found that information provision leads to modest increases in travel choice quality, especially when the information makes travelers aware of travel alternatives that were previously unknown to them (Chorus et al., 2007a). Furthermore, ICT applications may also increase travel: The shorter routes or increased convenience may reduce generalized transport costs (GTC), inducing demand. Navigation systems, for example, could release a latent demand for travel because they reduce travel times, the inconvenience of searching, and maybe also the fear of getting lost. They could also generate travel by showing route opportunities the traveler was not aware of (leading to detours) or more scenic but longer routes.

\section{$2.4 \quad$ Social impacts}

Another category of the literature focuses on the social impact of Internet use and activities. Note that this paper is on travel behavior impacts, and that social impacts are a separate category of impacts. However, for reasons of completeness we will also briefly discuss the social impact of Internet use. Internet use has been linked with negative social effects, including a decrease in both social interaction and in the quality of the activity experience (Kraut et al., 1998; Kenyon and Lyons, 2007). Internet-based ICT can also enrich people contacts because it is possible to communicate with people who would not otherwise be physically accessible, examples being finding old friends, meeting new people, and enabling more frequent interaction with personal and professional contacts. Kraut et al. (2002) indicate that the debate about the social impact of ICT is not yet finished. Another positive social effect of ICT may be that if someone gets information that a bus or train is delayed, waiting time is reduced, which reduces travel times but can also increase perceived social safety.

\subsection{Summarizing table}

Table 1 summarizes the main findings over section 2 .
Table 1: Main findings of the overview of literature of the impact of ICT on travel behavior

\begin{tabular}{ccc}
\hline Topic & Main empirical findings & Gaps \\
\hline $\begin{array}{c}\text { Substitution - } \\
\text { complementarity }\end{array}$ & $\begin{array}{c}\text { Complementarity is } \\
\text { more important than } \\
\text { substitution }\end{array}$ & Well studied \\
$\begin{array}{c}\text { Multitasking, } \\
\text { fragmentation }\end{array}$ & $\begin{array}{c}\text { ICT leads to a reorgani- } \\
\text { zation of activities and } \\
\text { travel in time and space }\end{array}$ & Poorly understood \\
$\begin{array}{c}\text { Travel mode, route } \\
\text { and departure-time } \\
\text { choice }\end{array}$ & $\begin{array}{c}\text { High policy expectations } \\
\text { were too optimistic }\end{array}$ & $\begin{array}{c}\text { Awareness of satnav } \\
\text { information is a blind } \\
\text { spot }\end{array}$ \\
& & $\begin{array}{c}\text { Might induce demand } \\
\end{array}$
\end{tabular}

\section{Accessibility: an overview of literature}

Several authors have written review articles on accessibility measures, often focusing on a particular category of accessibility, like location accessibility (e.g., Song, 1996; Handy and Niemeier, 1997), individual accessibility (e.g., Pirie, 1979; Kwan, 1998) or economic benefits of accessibility (e.g., Koenig, 1980; Niemeier, 1997). Here we use the review of Geurs and van Wee (2004), (from here on GvW), as a point of departure. Their review differs from other review articles, first because accessibility measures are reviewed from different perspectives (land-use, transport, and social as well as economic impacts) instead of focusing on one specific perspective. Second, measures are reviewed according to a broad range of relevant criteria: (a) theoretical soundness, (b) interpretability and communicability, (c) data requirements, and (d) usability in social and economic evaluations. We consider this approach a useful point of departure to understand the potential impact of ICT on accessibility. The aim of the section is to give a summary of GvW's paper and to give an overview of three important developments since the paper was written that hasten the need for an update.

The definition of accessibility given by GvW is presented above. Note that we exclude goods transport in this paper, and therefore also in the definition we use for this paper. Note also that $\mathrm{GvW}$ use the term 'accessibility' when using a locations perspective, as opposed to 'access' that assumes a person's perspective. In other words, a location is accessible by people, whereas a person has access to locations. ICT can impact both accessibility and access. For example, the accessibility of a city center can increase due to ICT-based dynamic parking information systems, increasing access for individuals. In this paper we use the term accessibility for both the location and the person perspective. 
As already mentioned in the introduction, GvW distinguish four components of accessibility that they derive from the literature:

The land-use component reflects the land-use system, consisting of (a) the amount, quality, and spatial distribution of opportunities supplied at each destination (jobs, shops, health, social, recreational facilities, etc.), (b) the demand for these opportunities at origin locations (e.g., where inhabitants live), (c) the confrontation of supply and demand for opportunities that may result in competition for and between activities with restricted capacity such as jobs, labor force, school vacancies, and hospital beds (van Wee et al., 2001).

The transportation component describes the transport system, expressed as the disutility experienced by an individual when covering the distance between an origin and a destination; included are the amount of time (travel, waiting, parking), costs (fixed and variable), and comfort-related variables (such as reliability, level of comfort, accident risk, etc.). This disutility partly results from the confrontation between supply of and demand for infrastructure capacity. The supply of infrastructure includes its location and characteristics (e.g., maximum travel speed, number of lanes, public transport timetables, and travel costs). The demand relates to both passenger and freight travel.

The temporal component reflects the temporal constraints, i.e., the availability of opportunities at different times of day and the time available for individuals to participate in certain activities (e.g., work and recreation). Note that this temporal component has become increasingly popular among academics in transportation and geography (e.g., Ettema et al., 2007; Schwanen and Kwan, 2008; Neutens, 2010).

The individual component reflects the needs (depending on age, income, educational level, household situation, etc.), abilities (depending on people's physical condition, availability of travel modes, etc.), and opportunities (depending on people's income, travel budget, educational level, etc.) of individuals. These characteristics influence a person's level of access to transport modes (e.g., being able to drive and borrow/use a car) and spatially distributed opportunities (e.g., have the skills or education to qualify for jobs near their residential area), and may strongly influence the total aggregate accessibility result.

$\mathrm{GvW}$ state that these four components interact. For example, the impact of temporal constraints, such as the opening times of shops, on an individual might be less important if (s) he belongs to a household with another member who can do the shopping. And changes in the transport system can induce changes in the land-use system as well, addressed in the land use transport interaction literature. Furthermore, GvW state that an accessibility measure should ideally take all compo- nents and elements within these components into account, although in practice applied accessibility measures only focus on one or a selection of components. GvW identify four categories of measures for accessibility: (a) infrastructure-based measures, including level-of-service indicators, such as travel speeds and congestion levels, (b) location-based measures, analyzing accessibility at locations, typically on a macro-level, an example being contour measures, such as the number of jobs accessible by car within 30 minutes, (c) person-based measures analyzing accessibility at the individual level (based on the space-time geography of Hägerstrand, 1970), and (4) utility-based measures, analyzing the economic benefits that people derive from access to spatially distributed activities.

We consider there to have been three important developments in understanding the current state of the art of accessibility measures and their applications since the publication of the paper by $\mathrm{GvW}$ in 2004 . First, and directly related to the aims of this paper, it should be noted that the definition used in GvW relates only to physical accessibility. In recent years the impact of ICT on travel behavior and - though not explicitly-accessibility has gained increasing attention, as reflected by the special issue on the interaction between ICT and human activity travel behavior in Transportation Research Part A (for the editorial, see Kwan et al., 2007; see references to papers elsewhere in this paper), and the special issue in the Journal of Transport Geography (Lyons, 2009; see references to papers elsewhere in this paper). Second, progress has been made in the area of the utility-based measures, in particular the logsum-based measures (see De Jong et al., 2007, for an overview). The logsum approach allows the researcher to relatively elegantly derive the utility of accessibility from the logsum of random-utility based discrete choice travel models. Since the conceptual idea that the logsum can be interpreted as an accessibility measure was launched (Ben-Akiva and Lerman, 1985), it has been frequently used in academia (see Geurs et al., 2010; Dong et al., 2006, for example), though it is less popular among practitioners. Third, progress has been made in personbased measures. For example, Dong et al. (2006) introduced a measure for accessibility to all activities in which an individual engages, incorporating constraints, such as scheduling, and travel characteristics, such as trip chaining. Veldhuisen et al. (2005) and Arentze et al. (2008) contributed to the practical applicability of such a measure, demonstrating the possibilities of synthetic data, thereby reducing the huge barrier created by the enormous data collection effort that these measures normally require.

We think the second and third developments fit the categorization of $\mathrm{GvW}$. Before elaborating on the potential impacts of ICT on accessibility, we will first provide an overview of 
categorizations of ICT that could potentially be relevant from an accessibility perspective.

\section{Potential impacts of ICT on accessibility}

If one wants to categorize ICT in the context of its impact on travel behavior, a major challenge is to select the primary key for categorization. Examples of such keys include: information technologies versus communication technologies, trip-based impact versus activity-based impact of ICT, portable versus non-portable ICT devices, personal devices versus non-personal ICT. Here we use a hybrid categorization by distinguishing between three types of ICT:

1. PC use at fixed locations for information and communication;

2. Individual mobile devices, such as laptops and PDAs for information and communication;

3. Infrastructure-related information provision technologies, such as dynamic route information panels (DRIPS) for roads and public transport travel information.

We will argue that these three types of ICT can impact on all four components of accessibility as presented in GvW. We discuss the impact of ICT on accessibility, distinguishing these components. For a visualization, the reader is referred to Figure 1 , which presents a conceptual model of the hypothesized relations (section 5).

\subsection{The transport component}

ICT can reduce travel resistance in many ways. First, a traveler may access travel information before the trip is available via individual ICT devices (PCs, PDAs, and the like). This can be done via web-based information (PC at fixed locations or portables) or via mobile devices. As a result of receiving the information the traveler can leave the point of origin 'just in time,' reducing access time. In addition, the 'optimal' route can be selected for several modes (car, public transport, and air travel) as well as for multi-modal travel. Recent developments in mobile phone technologies (phones incorporating GPS and sensors) make it possible to develop personalized information provisions, which recognize the user and provide advice based on his/her situation context (e.g., vehicle status, real-time traffic, and weather conditions). Note that transport resistance is not the same as travel time. We use generalized transport costs (GTC) as the term to express transport resistances, including also components such as monetary costs, reliability, and comfort.
Second, ICT can help reduce travel resistance while traveling by providing 'en-route' information via individual mobile sources. Here we define en route as beginning the moment the traveler starts traveling. For example, if there are delays on public transport, a traveler might be able to find out if there is another way of continuing the trip that would be better than the original plan, e.g., by switching modes. Satellite navigation (satnav) systems can provide information for car users on delays and also advice on alternative routes that could reduce his/ her GTC. Note that on-trip information can be obtained on the traveler's initiative, although technology can also provide information not explicitly asked for, such as sending a text or short message service (SMS) because of an unexpected delay. Interestingly, in the context of frequently made trips, such as commuter trips, travelers have been found to prefer such early warning information more than information that forces them to take the initiative (Chorus et al., 2007b). A special case of en-route individual travel information is vehicle-to-vehicle communications systems. We categorize such systems as 'individual mobile devices.'

Third, ICT can help reduce travel resistance while traveling via nonindividual infrastructure-based ICT, such as DRIPS providing information about the road network or about train options. So, the road manager can influence accessibility via ICT. At public transport nodal points (such as stations), DRIPS can give dynamic information on bus, tram, or metro connections as well as on train connections. We also consider the ICT use that informs the railway personnel as an example of this category: Thanks to ICT, train personnel can provide travelers with travel information via train speakers.

Following the concept of GTC, we include any impact of travel resistance, not necessarily only travel time and the related costs. In addition, the comfort of the traveler matters. We think the impact of ICT on comfort is a relatively under-researched area. Below we give some examples of the impact of ICT on comfort. First, even without any change in travel times or costs, the traveler might appreciate receiving information on delays, so that (s)he can phone, e-mail, or SMS to let people know at the destination end of the trip that (s)he is delayed. Second, (s) he might change activities while traveling because (s)he knows about the delays. Assume a train traveler expects to arrive at a station in 10 minutes. This might be too short to decide to start work using a laptop. But if there is a serious delay and (s)he knows the train trip will take an additional 45 minutes, (s)he might decide to start using a laptop. Third, route information might increase comfort even if no change in the routes is made, because the traveler might appreciate knowing (s)he has chosen the 'right' route. In general, the importance of these aspects follows from the notion that travelers dislike uncertainty per se 
(i.e., are risk averse). The existence of this dislike of uncertainty has been well documented in the context of travel time uncertainty (e.g., Lam and Small, 2001; Bates et al., 2001; Rietveld et al., 2001; Brownstone and Small, 2005) as well as the travel costs uncertainty and uncertainty about waiting times (e.g., Chorus et al., 2010).

\subsection{The land-use component}

This component is important at three levels. First, it is generally recognized that the transport system and the land-use system interact (e.g., Wegener and Fürst, 1999). If, thanks to ICT, transport resistances are reduced, land-use changes can be expected. For example, it might impact on the locations for new office areas or shops. Second, ICT may have an impact on the distribution of actors over the given locations of destinations. In this case land use itself is not influenced by ICT but the distribution of, for example, households over houses, companies over offices, or companies over industrial areas. (See Argiolu et al., 2008, for a case study into this latter type of ICT impact, focusing on intelligent transportation systems.) Third, ICT might impact on which persons carry out which activities at which locations. This third category can be split into subcategories: A person (or household) may change (a) activities, or (b) the location of activities. Examples of (a) include decisions not to visit friends or family because of a road accident resulting in long delays, the decision to meet someone after ICT-based contacts, and the decision to bring children to school because the person will then work at home using ICT instead of at the office. Examples of (b) include the decision to work at home using ICT instead of traveling to work and the decision to buy a used car at another dealer found via the web. Though not based on empirical evidence, we have the impression that in particular the impact of ICT on nonwork related activity and destination choices is potentially large, and certainly under-researched. For example, thanks to ICT, people are aware of concerts and of new or second-hand goods over a large area, people meet people using ICT that they then might want to visit, select different holiday destinations, etc. ICT can therefore certainly have an impact on nonwork related activity and travel behavior, and indirectly also on accessibility via the land-use component. Even without the first two categories of ICT impacts (land-use changes and the distribution of actors over locations), ICT potentially has a large impact on the awareness and valuation of location-based activities at numerous locations.

\subsection{The temporal component}

As mentioned above, the temporal component relates to the availability of opportunities at different times of day and the time available for individuals to participate in certain activities (e.g., work or recreation). ICT can have an impact on both. First, the availability of opportunities at different times of day: Thanks to ICT, a lot of activities can be carried out at other times of the day. Nowadays many people work outside the official office hours, e.g., in the evening or on the weekend, with ICT providing them with access to work-related networks or connections to colleagues or business partners. In addition, people can use the web at any time to search for information about products that they might wish to buy. Second, the time available for activities might change. If ICT allows the traveler to travel more efficiently, (s)he might have more time to spend on other activities. Note that the impact of ICT on overall travel time reductions is probably very small, following the theory of constant travel time budgets (e.g., Szalai, et al., 1972; Zahavi and Talvhitie, 1980; Shafer and Victor, 1997; Mokhtarian and Chen, 2004). But even if people decide to use the potential travel time savings, thanks to ICT, to travel more, they certainly appreciate doing so. This reduced travel time reduction still increases their accessibility. Note that related utility changes can be estimated easily using utility-based measures, including the logsum-based measures. In addition, ICT can allow a person to save time by combining work and travel, e.g., by using a laptop for work while traveling by train or by carrying out business calls while driving. This impact of ICT has both a transport (resistance) and temporal component.

ICT can also save time because work can be carried out more efficiently. The time savings probably will be used to increase productivity rather than work-time reductions.

\subsection{The individual component}

People's wants, needs, preferences, and abilities are highly personal. It is therefore obvious to most researchers that accessibility measures should include an individual component. Following the description of the individual component above, ICT can first have an impact on the needs (and wants) of people: People might, for example, want to go to a concert they are aware of thanks to ICT. Second, ICT can have an impact on people's abilities, in particular, disabled people. For example, people not able to drive a car (anymore) might be able to travel using ICT for travel on demand, increasing their accessibility. Both the use of new technologies (such as new forms of ICTs) and activity-travel behavior of individuals (and as a result, individual accessibility) are heavily influenced by the social networks in which they participate. (See Dugundji et al., 2008, for an editorial of a special issue on this topic.) Unfortunately, the increases in behavioral realism in studies by incorporating 
social-network aspects of accessibility induce quite substantial increases in complexity in terms of both model development and data collection.

\subsection{Interactions}

Following GvW the accessibility components all interact in both directions. For example, the land-use and resistance components interact: Transport system characteristics, including travel resistances, have an impact on land use, and land use has an impact on the transport system. We refer to GvW for a conceptualization and further description of these interactions. Here, we conclude that the literature on the impact of ICT on travel behavior and accessibility addresses the direct impact of ICT but fails to incorporate the impact due to the interactions between the accessibility components. For example, multitasking while traveling by train may reduce transport resistance, improving the competitive position of the train compared to the car, making residential areas near railway stations more attractive, leading to more of such areas being built.

\subsection{Summarizing table}

Table 2 summarizes the main findings over section 4 .

\section{A conceptual model for the impact of ICT on accessibility}

Previous categorizations and conceptualizations of the impact of ICT focus on travel behavior (e.g., Salomon, 1986; Mokhtarian and Salomon, 2002; Mokhtarian, 2003; Choo and Mokhtarian, 2005; Nobis and Lenz, 2009). To the authors' knowledge a conceptualization of the impact of ICT on accessibility, focusing on all the components addressed above, does not exist. Figure 1 illustrates these impacts and includes both the direct and indirect relationships (dotted lines) with ICT. Figure 1 summarizes key aspects of the text above, and shows that PCs at fixed locations and mobile devices both have a direct impact on all four components of accessibility, as explained above. Infrastructure-related information provision directly affects transport resistance, for example, via DRIPS. Mobile and fixed locations ICT options can reduce transport resistance by showing information on travel options, travel times, and route choice and by providing options for multitasking (see above). They can influence the land-use component by providing the user with information about which activities are available at which locations, possibly leading to changes in location choices. They can influence the temporal component by giving access to, for example, the work network or shopping options 24 hours per day and by providing options for multitasking,

Table 2: Overview of potential impacts of ICT on accessibility.

\begin{tabular}{|c|c|c|c|}
\hline Component & Key impact of ICT & Subcategories of impacts & Dominant gaps \\
\hline \multirow[t]{3}{*}{ Transport component } & Reduce travel resistance & Pre-trip travel information & $\begin{array}{l}\text { Comfort impacts poorly } \\
\text { understood }\end{array}$ \\
\hline & & En-route travel information & \\
\hline & & $\begin{array}{l}\text { En-route infrastructure-based } \\
\text { travel information }\end{array}$ & \\
\hline \multirow[t]{3}{*}{ Land-use component } & $\begin{array}{l}\text { Changes due to land-use and } \\
\text { transport interaction }\end{array}$ & & $\begin{array}{l}\text { Land-use transport interac- } \\
\text { tion often studies but not } \\
\text { the specific ICT-related } \\
\text { changes }\end{array}$ \\
\hline & $\begin{array}{l}\text { Change of distribution of ac- } \\
\text { tors over the given locations of } \\
\text { destinations }\end{array}$ & Activities & \\
\hline & $\begin{array}{l}\text { Change which persons carry } \\
\text { out which activities at which } \\
\text { locations. }\end{array}$ & Locations of activities & \\
\hline \multirow[t]{2}{*}{ Temporal component } & $\begin{array}{l}\text { Changes in availability of op- } \\
\text { portunities at different times of } \\
\text { the day }\end{array}$ & & Not well understood yet \\
\hline & $\begin{array}{l}\text { Changes in time available for in- } \\
\text { dividuals to participate in certain } \\
\text { activities }\end{array}$ & & \\
\hline \multirow[t]{2}{*}{ Individual component } & $\begin{array}{l}\text { Change in needs and wants of } \\
\text { people }\end{array}$ & & Not well understood yet \\
\hline & $\begin{array}{l}\text { Impact on people's abilities } \\
\text { (disabled) }\end{array}$ & & \\
\hline Interactions & All components interact & & Poorly understood \\
\hline
\end{tabular}


increasing the time available for related tasks and the temporal availability of options. They can influence the individual component by changing the needs and wants of people, for example, having electronic contact with others or by giving people access to opportunities that otherwise would not be available for them. Figure 1 shows that the four components of accessibility all have mutual impacts, as already explained in Sections 3 and 4.5. As a result ICT options, in addition to direct effects, have many indirect effects via interactions between the components of accessibility.

Figure 1: ICT's impact on the components of accessibility (dotted lines are indirect effects)

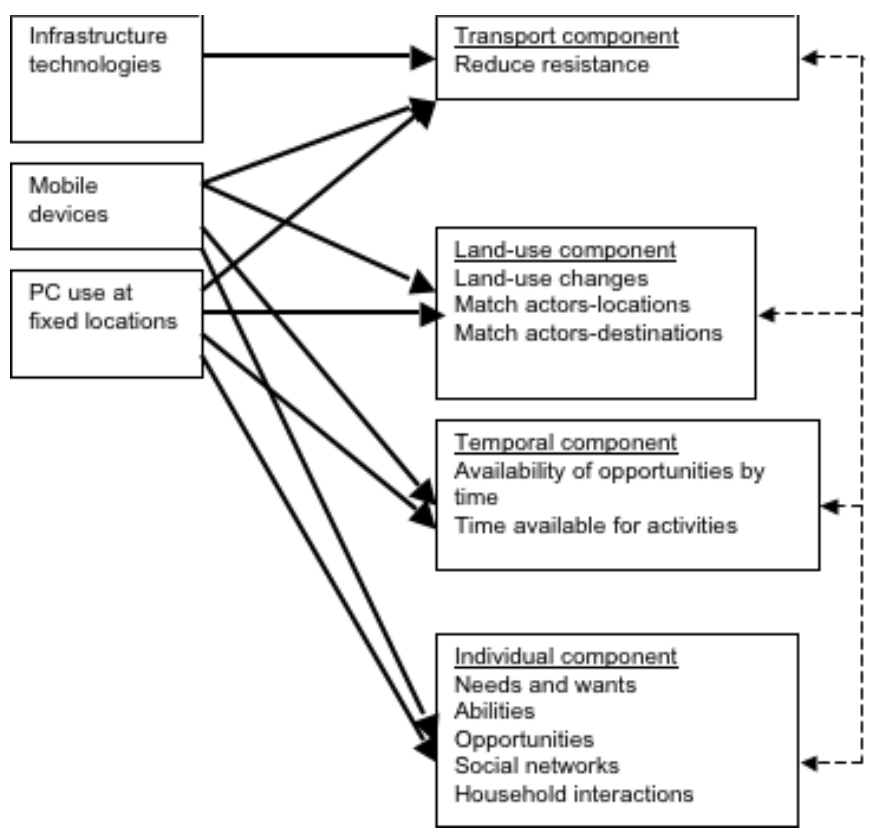

\section{Toward a research agenda}

We first address some promising areas of research in the area of ICT and travel behavior, followed by examining the implications for that particular research field of the impact of ICT on accessibility. The areas related to ICT and travel behavior can be split into methodological versus content-related areas.

The first methodological area for future research is the broadening of system boundaries. Most research into the area of travel behavior only partially considers travel behavior. For example, only the interaction between e-shopping and shopping trips are considered, or the impact of ICT on commuting behavior. Literature that assumes less limiting system boundaries is relatively scarce, exceptions being Mokhtarian and Meenakshisundaram (1999), Choo and Mokhtarian (2005), Choo et al. (2007), and Lee and Mokhtarian (2008). However, as- suming theories on constant travel time budgets (e.g., Mokhtarian and Chen, 2004), it is very likely that the substitution or generation effects of ICT for specific trip purposes will also have implications for travel behavior for other trips. The paper by Weltevreden and Rotem-Mindali (2009) uses broad system boundaries when considering the impact of e-commerce not only on personal travel but also on freight travel. In the case of business-to-consumers (b2c) e-commerce, they conclude that the reduction in personal travel was not fully compensated by the increase in freight transport. In the case of consumer-toconsumer (c2c) e-commerce, both personal travel and freight transport increased. Second, we consider it likely that within homogeneous groups of people (e.g., based on gender, age, and income) self-selection with respect to ICT use in its several forms (see Figure 1) can occur. Residential self-selection is now a generally recognized concept (e.g., Mokhtarian and Cao, 2008; Cao et al., 2009), but as van Wee (2009) argues, self-selection can occur in several other ways, often-but not exclusively - related to attitudes, in this case toward the use of ICT in its several forms, and to related behavior. Self-selection can, for example, occur because some people might be more inclined than average to use ICT as a substitute for physical accessibility, online shopping or Skype-based communication being examples. Insights into self-selection and ICT can, for example, improve our understanding of the extent to which early adopters' behavior can be scaled-up to the wider population. Due to potential self-selection the results for early adopters do not necessarily apply equally to the whole population. In addition, as suggested by Ettema and Verschuren (2007) the underlying causality between ICT and multitasking is not fully clear and can be confounded with attitudes related to multitasking.

Content-related future research could first study the interactions between members of a household, which are important for accessibility, in general, and also for the impact of ICT on accessibility. These interactions are not only content related but also have important methodological consequences. As mentioned above, a person might have temporal constraints that can be solved by other members of the household. (See Ettema et al., 2007, for an empirical study on this topic.) For example, shopping, picking up children from school, and receiving (b2c-ordered) packages while working can for many persons be shared between members of a household (substitution). The substitution of tasks is also possible between persons belonging to the non-household related social contacts, such as neighbors, other parents, the wider family, and friends. ICT can improve the substitution between persons, e.g., by using mobile phones for calling or SMS, or sending e-mails. In particular, the often rigid person accessibility measures based on time 
geography might benefit from including such inter-person substitutions. The importance of considering mobility choices at the household level, rather than at the individual level, has gained increasing momentum. (See Timmermans and Zhang, 2009, for an editorial of a special issue on the topic.) However, as was noted in the context of studies at the higher level of social networks, it is clear that abandoning the individual as a unit of analysis leads to large increases in complexity.

Second, future research could advance our understanding of the role of ICT in relieving the pain of congestion. Literature well addresses that ICT might lead to making trips at a different time of day, or even not at all. Consequently, ICT could reduce congestion. In addition to this positive effect of ICT, we would argue that even if ICT had no impact on congestion levels, ICT can relieve the burden of congestion by giving people the option to avoid it by traveling at another time or not at all (and work at home) or by making the time spent in congestion more productive. An extreme situation is that people might intend to go to work, but thanks to ICT they become aware of, for example, a road block leading to extreme congestion and decide not to travel but work from home. In other words, ICT in this case would prevent them making a trip for which the disutility of travel is bigger than the utility of the activity (more precisely: performing the activity at that specific place). A third content-related gap in the literature is the impact of ICT on the comfort of traveling, as already mentioned in section 4. The further development in personalized information provisions using mobile phone technologies, in particular, will increase the comfort of traveling. For example, if people receive a message about a delay to their train while they are traveling, they can let others know about their delay and reduce their travel-related stress. ICT-related multitasking might also make traveling more comfortable. With the fast penetration of smartphones-Berg Insight (2010) forecasts that by 201460 percent of new phones sold worldwide will be GPS enabledthis new type of ICT is likely to become more important than PC use at fixed locations. To the authors' knowledge this is a blind spot in the scientific literature, although theoretical and empirical efforts have been made to study this potential impact of ICT (Jain and Lyons, 2008). Fourth, a further gap in research in our opinion is the impact of ICT on non-adults. Some studies reveal first insights. Based on a study on media use by young people in the US, Foehr (2006) concludes that young people are more likely to media multitask than others. At least some of their media time is shared between more than one medium. Computer tasks are the most multitasked activities. Thulin and Vilhelmson (2005) studied ICT use by young people in Gothenburg, Sweden, concluding that they use computers on average for one and a half hours per day, and that ICT use generates additional contacts and communication rather than replacing telephone calls and travel. We think developments in these areas need to be monitored well because ICT changes rapidly as do trends among young people. This is important first because of the lack of knowledge itself. In addition, a life-cycle effect related to young people might occur: ICT-related impacts on travel and activity behavior as experienced in the non-adult years might have an impact on the future behavior of this population.

Up until now we have elaborated on research gaps in the area of ICT and travel behavior. We now focus on gaps related to the impact of ICT on accessibility. Partly related to the gaps in the literature addressed above, another area of further research relates to developing accessibility measures and indicators integrating physical and ICT accessibility. Examples of work in this area include Shaw and Yu (2009) who integrated time geography concepts, GIS, and activities and interactions in a hybrid physical-virtual space. Nagurney et al. (2002) develop a multi-criteria network equilibrium framework for modeling decision making in the Information Age. They apply their framework to telecommuting versus commuting and to teleshopping versus shopping decision-making. Partly, inspired by these examples, we think a distinction can be made between (1) measures and indicators for the combined ICT and physical access of opportunities, and (2) measures of access to ICT not having a functional physical equivalent. The latter category can probably be ignored sometimes for travel behavior related approaches. However, there might be an impact on travel because related activities might compete with others that require traveling. So, an indirect effect of these ICT activities on travel behavior might occur. Development of new accessibility measures and indicators could focus on: (1) complementarity versus substitution, (2) multitasking while traveling, reducing transport resistance, (3) the positive impact of ICT on accessibility by reducing GTC, e.g., by making travelers aware of recent changes in the transport system, such as new transit alternatives, and (4) interactions between members of households, or even wider social interactions. With respect to the combined impact of ICT and physical travel, we suggest a multilevel approach for indicators. At the bottom level accessibility might be a function of (a) the physical components, including land use and transport, (b) the ICT-component, and (c) interactions between (a) and (b). Of course, the interactions are the most challenging. For example, to what extent can poor physical access to the shops be compensated for by e-shopping? At this level separate indicators for different activities, such as shopping, working, or social contacts, can be developed. At a higher level such indicators for different activities might be integrated. To put it more formally: Accessibility for combined 
activities might be a function of (a) the accessibility of distinguished activities separately and (b) interactions between the accessibility of different activities. Again the interactions are the most challenging. An example of interactions might be a commuter who is considering changing her/his working hours so that (s)he starts and finishes late because (s)he wishes to avoid congestion and because e-shopping allows her/him to avoid visiting the supermarket. At the highest level, interactions between members of households (or local communities or other networks) could be included. We realize it is much easier for us to give this overview than to formalize accessibility this way in practice, including data collection and analyses. For data collection we think stated preference techniques (including stated choice) might be a fruitful way to estimate the interactions between ICT and physical access, allowing an estimate of the trade offs and compensation options. Within these research challenges the impacts of ICT on travel behavior are also relevant. For example, the explicit inclusion of constant travel time budgets is challenging: Will they remain constant in scenarios with a high level of ICT-use? If so, what are the implications for accessibility indicators? If not, why not, and what are the implications for travel behavior (and related externalities) and accessibility? Maybe in addition to the willingness to pay for travel time reductions, researchers should study the 'willingness to travel longer, as a function of multitasking' (see section 2.2). As addressed above, multitasking while traveling can also have an impact on VoTTS. We agree with Ettema and Verschuren (2007) who suggest that time pressure could be related to ICTbased multitasking while traveling, and could have an impact on the marginal value of time (VOT). This impact is not only relevant for accessibility and travel behavior, but also for VOT studies and their use in, for example, cost-benefit analyses.

Within category (1) we think first of all that new indicators could be developed for accessibility itself. In addition, measures for the utility of accessibility could be developed. We think a major challenge is to develop activity-based models including ICT in its several forms and roles (including its complementarity and substitution roles), possibly building on the work of Dong et al. (2006). If such models were developed, the logsum approach might be an attractive way forward to evaluate the above-mentioned utility.

Furthermore, accessibility analysis techniques are also likely to consider the use of smartphones for detailed individual data collection and the analysis of travel behavior, accessibility, and the role of attributes of the physical environment in accessibility. ICT thus not only improves the comfort of travel for mobile phone users but also provides great opportunities for researchers to improve the quality of accessibility analysis.

A special topic in the area of ICT and accessibility might be the (potential) links between ICT and road pricing, and their combined effect on accessibility. Thanks to ICT, the discrepancies between the theoretical first best and the practically feasible road-pricing options might decrease. ICT will enable more dynamics in pricing and related communications, and provide the road user with advice, which combines prices and travel times. Options for ICT and pricing, and their combined effect on accessibility are not only promising because of accessibility issues, but also because of welfare and acceptability issues.

Another special topic might be the role of the employer. The employer can play a crucial role in reducing barriers to use of ICT as a substitute for working at the job location, either for part of the day (e.g., the first two hours of the day, to avoid congestion or high road pricing fees) or the whole day. Relevant research topics could include 'hard' employer's measures like providing employees with ICT facilities (home computer, Internet, and work network connections) or compensation for commuting costs and also 'soft' topics like the culture with respect to teleworking.

As mentioned in the introduction we exclude goods transport. Though this is beyond the scope of this paper, we think a lot of research challenges relate to the impact of ICT on accessibility as far as goods transport is concerned, e.g., access to markets (buying and selling) in general; cultural, legal, and institutional barriers limiting access to markets; and product information. See Denant-Boèmont and Hammiche (2010) for an early attempt at modeling some of these ICT-related impacts. 
Table 3 summarizes and categorizes our research recommendations.

Table 3: An overview of research recommendations.

\begin{tabular}{|c|c|c|}
\hline Category of recommendation & Type of recommendation & Why important? \\
\hline \multirow[t]{2}{*}{ Methodology related } & The broadening of system boundaries & $\begin{array}{l}\text { Categories of travel behavior interact. Ignoring this interaction } \\
\text { might lead to 'wrong' conclusions }\end{array}$ \\
\hline & ICT-related self-selection & $\begin{array}{l}\text { Ignoring the phenomenon of self-selection could lead to 'wrong' } \\
\text { conclusions }\end{array}$ \\
\hline \multirow[t]{4}{*}{ Content related } & $\begin{array}{l}\text { Interactions between members of house- } \\
\text { holds, and other social interactions }\end{array}$ & $\begin{array}{l}\text { These interactions are important for accessibility, but poorly } \\
\text { understood }\end{array}$ \\
\hline & ICT relieving the pain of congestion & Poorly understood \\
\hline & Impact of ICT on the comfort of traveling & Poorly understood \\
\hline & Impact of ICT on non-adults & Poorly understood \\
\hline \multirow[t]{2}{*}{ Impact of ICT on accessibility } & $\begin{array}{l}\text { Developing accessibility measures and } \\
\text { indicators integrating physical and ICT } \\
\text { accessibility }\end{array}$ & $\begin{array}{l}\text { Current indicators do not or poorly include (1) complementarity } \\
\text { versus substitution, (2) multitasking while traveling, reducing } \\
\text { transport resistance, ( } 3 \text { ) the positive impact of ICT on accessibil- } \\
\text { ity by reducing GTC, e.g., by making travelers aware of recent } \\
\text { changes in the transport system such as new transit alternatives, } \\
\text { (4) interactions among members of households, or even wider } \\
\text { social interactions }\end{array}$ \\
\hline & ICT and road pricing & $\begin{array}{l}\text { ICT might decrease the discrepancies between the theoretical } \\
\text { first best and the }\end{array}$ \\
\hline
\end{tabular}

\section{Conclusions and discussion}

Our first conclusion is that much more literature exists on the impacts of ICT on travel behavior than on its impact on accessibility. Second, we argue that ICT potentially has an impact on all four components of the concept of accessibility: (1) the land-use component, (2) the transportation component, (3) the temporal component, and (4) the individual component. We present an overview of challenges in the area of the impact of ICT on travel behavior. Third, a major challenge seems to be the development of accessibility measures and indicators that include ICT, including those that measure the utility of accessibility. Fourth, in the area of ICT's impact on travel behavior, many research gaps exist. Examples are the impact of ICT on overall activity and trip patterns, the impact of ICT on activities and trips at the household and social-network level, ICT as a means of avoiding congestion or mitigating its effects, and the role of the phenomenon of self-selection in the context of ICT use. Finally, a challenge for modeling exists: We think a major challenge is to develop models for activities, including ICT impacts, which combine high levels of behavioral realism with (econometric) tractability. In this regard it should be noted that for practitioners, let alone to communicate to policymakers and practitioners, behaviorally realistic models that are very hard to calibrate or validate are of limited value.

\section{Acknowledgements}

We wish to thank two reviewers for making a range of very constructive comments, which greatly helped us improve an earlier version of our paper.

\section{References}

Aguilera, A. 2008. Business travel and mobile workers. Transportation Research Part A, 42: 1109-1116. doi:10.1016/j. tra.2008.03.005

Albertson, L.A. 1977. Telecommunications as a travel substitute: Some psychological, organizational, and social aspects. Journal of Communication, 27(2): 32-43. doi: 10.1111/j.1460-2466.1977.tb01824.x

Altinkemer, K. 2001. Bundling E-Banking Services. Communications of the $A C M, 44(6): 45-47$.

Arentze, T.A., H.J.P. Timmermans, and F. Hofman. 2008. Creating synthetic household populations: Problems and approach. Transportation Research Record, 2014: 85-91. doi:10.3141/2014-11

Argiolu, R., R. van der Heijden, I. Bos, and V. Marchau. 2008. Intelligent transport systems and preferences for office locations. Environment and Planning Part A, 40(7): 17441759. doi: 10.1068/a39231 
Bates, J., J. Polak, P. Jones, and A. Cook. 2001. The valuation of reliability for personal travel. Transportation Research Part E, 37(2-3): 191-229. doi:10.1016/S1366-5545(00)00011-9

Ben-Akiva, M. and S. R. Lerman. 1985. Discrete choice analysis: Theory and application to travel demand. Cambridge, Mass: The MIT Press.

Bennison, D.J. 1988. Transport/telecommunication interactions: Empirical evidence from a videoconferencing field trial in the United Kingdom. Transportation Research Part A, 22(4): 291-300. doi:10.1016/0191-2607(88)90007-6

Berg Insight. 2010. GPS and mobile handsets. Summary. Gothenburg, Sweden: Berg Insight, Gothenburg, Sweden.

Boden, D. and H. Molotch. 1994. The compulsion of proximity. NowHere: Space, time and Modernity. Friedland, R. and D. Boden (Eds.). Berkeley, CA: UCLA Press.

Brownstone, D. and K.A. Small. 2005. Valuing time and reliability: Assessing the evidence from road pricing demonstrations. Transportation Research Part A, 39(4): 279-293. doi:10.1016/j.tra.2004.11.001

Cao, X., P.L. Mokhtarian, and S. Handy. 2009. Examining the impact of residential self-selection on travel behavior: A focus on empirical findings. Transport Reviews, 29(3): 359-395. doi:10.1080/01441640802539195

Chatterjee, K. and M. McDonald. 2004. Effectiveness of using variable message signs to disseminate dynamic traffic information: Evidence from fields trials in European cities. Transport Reviews, 24(5): 559-585. doi:10.1080/0144164042000196080

Choo, S. and P.L. Mokhtarian. 2005. Do telecommunications affect passenger travel or vice versa? Structural equation models of aggregate U.S. time series data using composite indexes. Transportation Research Record, 1926: 224-232. doi:10.3141/1926-26

Choo, S., T. Lee, and P.L. Mokhtarian. 2007. Do transportation and communications tend to be substitutes, complements, or neither? The U.S. consumer expenditures perspective, 1984-2002. Transportation Research Record, 2010: 121-132. doi: 10.3141/2010-14

Chorus, C.G., E.J.E. Molin, and G.P. van Wee. 2006a. Travel information as an instrument to change car-drivers' travel choices: A literature review. European Journal of Transport and Infrastructure Research, 6(4): 335-364.

Chorus, C.G., E.J.E. Molin, G.P. van Wee, T.A. Arentze, and H.J.P. Timmermans. 2006b. Responses to transit information among car-drivers: Regret-based models and simulations. Transportation Planning and Technology, 29(4): 249271. doi:10.1080/03081060600905434

Chorus, C.G., T.A. Arentze, and H.J.P. Timmermans. 2007a. Information impact on quality of multimodal travel choic- es: Conceptualizations and empirical analyses. Transportation, 34(6): 625-645. doi:10.1007/s11116-007-9120-1

Chorus, C.G., E.J.E. Molin, T.A. Arentze, H.J.P. Timmermans, and G.P. van Wee. 2007b. Travelers' need for information in traffic and transit: Results from a web-survey. Journal of Intelligent Transportation Systems, 11(2): 1-11. doi:10.1080/15472450701293841

Chorus, C.G., J.L. Walker, and M.E. Ben-Akiva. 2010. The value of travel information: A search-theoretic approach. Journal of Intelligent Transportation Systems, 14(3): 154 165. doi:10.1080/15472450.2010.484746

Commission of the European Communities. 2001. European transport policy for 2020: Time to decide. Luxembourg: Commission of the European Communities.

Couclelis, H. 2000. From sustainable transportation to sustainable accessibility: Can we avoid a new tragedy of the commons? Information, Place and Cyberspace, D.G. Janelle and D.C. Hodge (Eds.), 341-456. Berlin: Springer.

Day, L.H. 1973. An assessment of travel/communications substitutability. Futures, 5(6): 559-572. doi:10.1016/00163287(73)90020-7

De Graaff, T. and P. Rietveld. 2007. Substitution between working at home and out-of-home: The role of ICT and commuting cost. Transportation Research Part A, 41(2): 142-160. doi:10.1016/j.tra.2006.02.005

De Jong, G., A. Daly, M.A. Pieters, and T. Van der Hoorn. 2007. The logsum as an evaluation measure: Review of the literature and new results. Transportation Research Part A, 41(9): 874-889. doi:10.1016/j.tra.2006.10.002

Denant-Boèmont, L. and S. Hammiche. 2010. Flexibility of Individual Decisions in a Real-Option Setting: An Experimental Study of Transport Choice. Journal of Intelligent Transportation Systems, 14(3): 140-153. doi:10.1080/1547 2450.2010.484742

Department for Transport. 2004. The future of transport: A network for 2030. London: Department for Transport.

Dong, X., M.E. Ben-Akiva, J.L. Bowman, and J.L. Walker. 2006. Moving from trip-based to activity-based measures of accessibility. Transportation Research Part A, 40(2): 163180. doi:10.1016/j.tra.2005.05.002

Dugundji, E., A. Paez, and T.A. Arentze. 2008. Social networks, choices, mobility, and travel. Environment and Planning Part B, 35(6): 956-960. doi: 10.1068/b3506ged

Ettema, D. and L. Verschuren. 2007. Multitasking and value of travel time savings. Transportation Research Record, (2010): 19-25. doi:10.3141/2010-03

Ettema, D., T. Schwanen, and H.J.P. Timmermans. 2007. The effect of location, mobility and socio-demographic factors on task and time allocation of households. Transportation, 
34(1): 89-105. doi:10.1007/s11116-006-0007-3

Farag, S., T.T. Schwanen, M. Dijst, and J. Faber. 2007. Shopping online and/or in-store? A structural equation model of the relationships between e-shopping and in-store shopping. Transportation Research Part A, 41(2): 125-141. doi:10.1016/j.tra.2006.02.003

Farag, S. and G. Lyons. 2010. Explaining public transport information use when a car is available: Attitude theory empirically investigated. Transportation, 37(6): 897-913. doi:10.1007/s11116-010-9265-1

Federal Transit Administration. 2003. Customer preferences for transitATIS. Research report nr. FTA-OH-26-7015-2003.1. Washington, DC: Federal Transit Administration.

Ferrell, C.E. 2004. Home-based teleshoppers and shopping travel: Do teleshoppers travel less? Transportation Research Record, 1894: 241-248. doi:10.3141/1894-25

Foehr, U.G. 2006. Media Multitasking among American Youth: Prevalence, Predictors, and Pairings. Dissertation. Stanford University. http://www.kff.org/entmedia/upload/7592.pdf (downloaded 6-7-2011).

Geurs, K.T. and B. van Wee. 2004. Accessibility evaluation of land-use and transport strategies: Review and research directions. Journal of Transport Geography, 12(2): 127-140. doi:10.1016/j.jtrangeo.2003.10.005

Geurs, K., B. Zondag, G. De Jong, and M. de Bok. 2010. Accessibility appraisal of integrated land-use/transport policy strategies: More than just adding up travel time savings. Transportation Research Part D, 15(7): 382-393. doi: 10.1016/j.trd.2010.04.006

Graham, S. and S. Marvin. 1996. Telecommunications and the city, electronic spaces, urban places. New York: Routledge.

Hägerstrand, T. 1970. What about people in regional science? Papers of the Regional Science Association, 24(1): 6-21. doi:10.1007/BF01936872

Handy, S.L. and D.A. Niemeier. 1997. Measuring accessibility: An exploration of issues and alternatives. Environment and Planning A, 29(7): 1175-1194. doi:10.1068/a291175

Harkness, R. C. 1977. Technology Assessment of Telecommunications/Transportation Interactions. Stanford Research Institute, Menlo Park, CA.

Hjorthol, R. and M. Gripsrud. 2009. Home as a communication hub: The domestic use of ICT. Journal of Transport Geography, 17(2): 115-123. doi:10.1016/j.jtrangeo.2008.11.007

Jain, J. and G. Lyons. 2008. The gift of travel time. Journal of Transport Geography, 16(2): 81-89. doi:10.1016/j.jtrangeo.2007.05.001

Kenyon, S. 2006. The 'accessibility diary': Discussing a new methodological approach to understand the impact of
Internet use upon personal travel and activity participation. Journal of Transport Geography, 14(2): 123-134. doi:10.1016/j.jtrangeo.2005.10.005

Kenyon, S. and G. Lyons. 2007. Introducing multitasking to the study of travel and ICT: Examining its extent and assessing its potential importance. Transportation Research Part A, 41(2): 161-175. doi:10.1016/j.tra.2006.02.004

Koenig, J.G. 1980. Indicators of Urban Accessibility: Theory and Applications. Transportation, 9(2): 145-172. doi:10.1007/BF00167128

Kraemer, K.L. 1982. Telecommunications/transportation substitution and energy conservation (Part 1). Telecommunications Policy, (March): 39-59. doi:10.1016/03085961(82)90004-0

Kraut R., M. Patterson. V. Lundmark, S. Kiesler, T. Mukopadhyay, and W. Scherlis. 1998. Internet paradox. A social technology that reduces social involvement and psychological well-being? The American Psychologist, 53(9): 11171131. doi:10.1037//0003-066X.53.9.1017

Kraut, R., S. Kiesler, B. Boneva, J. Cummings, V. Helgeson, and A. Crawford. 2002. Internet Paradox Revisited. Journal of Social Issues, 58(1): 49-74. doi:10.1111/15404560.00248

Kwan, M-P. 1998. Space-time and Integral Measures of Individual Accessibility: A Comparative Analysis Using a Pointbased Framework. Geographical Analysis, 30(3): 191-216. doi:10.1111/j.1538-4632.1998.tb00396.x

Kwan, M.P., M. Dijst, and T. Schwanen. 2007. The interaction between ICT and human activity-travel behavior (guest editorial). Transportation Research Part A, 41(2): 121-124. doi:10.1016/j.tra.2006.02.002

Lam, T.C. and K.A. Small. 2001. The value of time and reliability: Measurement from a value pricing experiment. Transportation Research Part E, 37(2-3): 231-251. doi:10.1016/ S1366-5545(00)00016-8

Larsen, J., J. Urry, and K. Axhausen. 2007. Networks and tourism. Mobile and social life. Annals of Tourism Research, 34(1): 244-262. doi:10.1016/j.annals.2006.08.002

Lathey, C. 1975. Telecommunications Substitutability for Travel: An Energy Conservation Potential. Washington, DC: United States Department of Commerce, Office of Telecommunications.

Lee, T. and P.L. Mokhtarian. 2008. Correlations between industrial demands (direct and total) for communications and transportation in the U.S. economy 1947-1997. Transportation, 35(1): 1-22. doi:10.1007/s11116-007-9141-9

Lenz, B. and C. Nobis. 2007. The changing allocation of activities in space and time by the use of ICT-'Fragmentation' as a new concept and empirical results. Transportation Research 
Part A, 41(2): 190-204. doi:10.1016/j.tra.2006.03.004

Lyons, G. 2009. The reshaping of activities and mobility through new technologies. Journal of Transport Geography, 17(2): 81-82. doi:10.1016/j.jtrangeo.2008.12.001

Lyons, G., J. Jain, and D. Holley. 2007. The use of travel time by rail passengers in Great Britain. Transportation Research Part A, 41(2): 107-120. doi:10.1016/j.tra.2006.05.012

Metz, D. 2008. The myth of travel time saving. Transport Reviews, 28(3): 321-336. doi:10.1080/01441640701642348

Mokhtarian, P.L. 1988. An empirical evaluation of the travel impacts of teleconferencing. Transportation Research Part A, 22(4): 283-289. doi:10.1016/0191-2607(88)90006-4

Mokhtarian, P. L. 1991. Telecommuting and travel: State of the practice, state of the art. Transportation, 18(4): 319342. doi:10.1007/BF00186563

Mokhtarian, P. L. 2003. Telecommunications and travel: The case for complementarity. Journal of Industrial Ecology, 6(2): 43-57. doi:10.1162/108819802763471771

Mokhtarian, P. L. 2009. If telecommunication is such a good substitute for travel, why does congestion continue to get worse? Transportation Letters, 1(1): 1-17. doi:10.3328/ TL.2009.01.01.1-17

Mokhtarian, P.L. and X. Cao. 2008. Examining the impacts of residential self-selection on travel behavior: A focus on methodologies. Transportation Research Part B, 42(3): 204228. doi:10.1016/j.trb.2007.07.006

Mokhtarian, P.L. and C. Chen. 2004. TTB or not TTB that is the question: A review and analysis of the empirical literature on travel time (and money) budgets. Transportation Research Part A, 38(9-10): 643-675. doi:10.1016/j. tra.2003.12.004

Mokhtarian. P.L. and R. Meenakshisundaram. 1999. Beyond tele-substitution: Disaggregate longitudinal structural equations modeling of communication impacts. Transportation Research Part C, 7(1): 33-52. doi:10.1016/S0968090X(99)00010-8

Mokhtarian, P.L. and I. Salomon. 1997. Modelling the desire to telecommute: The importance of attitudinal factors in behavioural models. Transportation Research Part A, 31(1): 35-50. doi:10.1016/S0965-8564(96)00010-9

Mokhtarian, P.L. and I. Salomon. 2002. Emerging travel patterns: Do telecommunications make a difference? Perpetual Motion: Travel Behaviour Research Opportunities and Application Challenges, H.S. Mahmassani (ed.), 143-182. Amsterdam: Pergamon. doi:10.1016/B978-0080440446/50008-5

Mokhtarian, P.L. and K. Varma. 1998. The trade-off between trips and distance travelled in analyzing the emission impact of centre-based telecommuting. Transportation Research Part
D, 3(6): 419-428. doi:10.1016/S1361-9209(98)00018-2

Mokhtarian, P.L., I. Salomon, and S.L. Handy. 2006. The impacts of ICT on leisure activities and travel: A conceptual exploration. Transportation, 33(3): 263-289. doi:10.1007/ s11116-005-2305-6

Muhammed, S., T. de Jong, and H.F.L. Ottens. 2008. Job accessibility under the influence of information and communication technologies, in the Netherlands. Journal of Transport Geography, 16(3): 203-216. doi:10.1016/j.jtrangeo.2007.05.005

Nagurney, A., J. Dong, and P.L. Mokhtarian. 2002. Multicriteria network equilibrium modelling with variable weights for decision-making in the Information Age, with applications to telecommuting and teleshopping. Journal of Economic Dynamics and Control, 26(9-10): 1629-1650. doi:10.1016/S0165-1889(01)00088-4

Neutens, T. 2010. Space, time and accessibility —Analyzing human activities and travel possibilities from a time-geographic perspective. Gent, Belgium: Department of Geography, University of Gent.

Niemeier, D.A. 1997. Accessibility: An evaluation using consumer welfare. Transportation, 24(4): 377-396.

Nobis, C. and B. Lenz. 2009. Communication and mobility behaviour - a trend and panel analysis of the correlation between mobile phone use and mobility. Journal of Transport Geography, 17(2): 93-103. doi:10.1016/j.jtrangeo.2008.11.013

Pick, J.B. and R. Azuri. 2008. Global digital device: Influence of socioeconomic, governmental, and accessibility factors on information technology. Information Technology for Development, 14(2): 91-115. doi: 10.1002/itdj.20095

Pirie, G.H. 1979. Measuring accessibility: A review and proposal. Environment and Planning Part A, 11: 299-312. doi:10.1068/a1 10299

Polishuk, P. 1975. Review of the impact of telecommunications substitutes for travel. IEEE Transactions on Communications, 23(10): 1089-1098. doi:10.1109/TCOM.1975.1092702

Rietveld, P., F.R. Bruinsma, and D.J. van Vuren. 2001. Coping with unreliability in public transport chains: A case study for Netherlands. Transportation Research Part A, 35 (6): 539-559. doi:10.1016/S0965-8564(00)00006-9

Rotem-Mindali, O. and I. Salomon. 2007. The impact of Eretail on the choice of shopping trips and delivery: Some preliminary findings. Transportation Research Part A, 41(2): 176-189. doi:10.1016/j.tra.2006.02.007

Salomon, I. 1986. Telecommunications and travel relationships: A review. Transportation Research Part A, 20(3): 223238. doi:10.1016/0191-2607(86)90096-8 
Schafer, A. and D. Victor. 1997. The Past and Future of Global Mobility. Scientific American, 227(4): 36-39. doi:10.1038/ scientificamerican1097-58

Schwanen, T. and M-P. Kwan. 2008. The Internet, mobile phone and space-time constraints. GeoForum, 39(3): 1362-1377. doi:10.1016/j.geoforum.2007.11.005

Shaw, S.L. and H. Yu. 2009. A GIS-based time-geographic approach of studying individual activities and interactions in a hybrid physical-virtual space. Journal of Transport Geography, 17(2): 141-149. doi:10.1016/j.jtrangeo.2008.11.012

Song, S. 1996. Some Tests of Alternative Accessibility Measures: A Population Density Approach. Land Economics, 72 (4): 474-482. doi: $10.2307 / 3146910$

Szalai A. (ed.). 1972. The use of time: daily activities of urban and suburban populations in twelve counties. The Hague: Mouton.

Timmermans, H.J.P. and J. Zhang. 2009. Modeling household activity travel behavior: Examples of state of the art modeling approaches and research agenda. Transportation Research Part B, 43(2): 187-190. doi:10.1016/j.trb.2008.06.004

Thulin, E. and B. Vilhelmson. 2005. Virtual mobility of urban youth: ICT-based communication in Sweden. Tijdschrift voor Economische en Sociale Geografie, 96(5): 477-487. doi:10.1111/j.1467-9663.2005.00480.x

van Wee, B. 2009. Self-selection: A key to a better understanding of location choices, travel behaviour and transport externalities? Transport Reviews, 29(3): 279-292. doi:10.1080/01441640902752961

van Wee, B., M. Hagoort, and J.A. Annema. 2001. Accessibility measures with competition. Journal of Transport Geography, 9(3): 199-208. doi:10.1016/S0966-6923(01)000102

van Wee, B., P. Rietveld, and H. Meurs. 2006. Is average daily travel time expenditure constant? In search of explanations for an increase in average travel time. Journal of Transport Geography, 14(2): 109-122. doi:10.1016/j.jtrangeo.2005.06.003

Veldhuisen, K.J., H.J.P. Timmermans, and L.L. Kapoen. 2005. Simulating the effects of urban development on activitytravel patterns: an application of Ramblas to the Randstad North Wing. Environment and Planning Part B, 32(4): 567-580. doi:10.1068/b30103

Wegener, M. and F. Fürst. 1999. Land-Use Transport Interaction: State of the Art. Deliverable D2a of the project TRANSLAND. Berichte aus den Insititut für Raumplanung, 46, Dortmund: Universität Dortmund, Insititut für Raumplanung. doi:10.2139/ssrn. 1434678

Weltevreden, J.W.J. and O. Rotem-Mindali. 2009. Mobility effects of b2b and c2c e-commerce in the Netherlands: A quantitative assessment. Journal of Transport Geography, 17(2): 83-92. doi: 10.1016/j.jtrangeo.2008.11.005

Zahavi, Y. and A. Talvitie. 1980. Regularities in travel time and money expenditures. Transportation Research Record, 750: $13-19$. 